\title{
Catalytic oxidation of cyclohexane to cyclohexanone and cyclohexanol by tert-butyl hydroperoxide over Pt/oxide catalysts
}

\author{
I REKKAB-HAMMOUMRAOUI, A CHOUKCHOU-BRAHAM*, \\ L PIRAULT-ROY ${ }^{\dagger}$ and C KAPPENSTEIN ${ }^{\dagger}$ \\ Laboratoire de Catalyse et Synthèse en Chimie Organique, Faculté des Sciences, Université A. Belkaid, \\ B.P. 119 Tlemcen 13000, Algeria \\ ${ }^{\dagger}$ LACCO UMR CNRS 6503, Laboratoire de Catalyse en Chimie Organique, Faculté des Sciences, \\ 86022 Poitiers Cedex, France
}

MS received 6 November 2010; revised 2 March 2011

\begin{abstract}
Heterogeneous oxidation of cyclohexane with tertiobutyl hydroperoxide was carried out on Pt/oxide $\left(\mathrm{Al}_{2} \mathrm{O}_{3}, \mathrm{TiO}_{2}\right.$ and $\left.\mathrm{ZrO}_{2}\right)$ catalysts in the presence of different solvents (acetic acid and acetonitrile). The catalysts were prepared using $\mathrm{Pt}\left(\mathrm{NH}_{3}\right)_{2}\left(\mathrm{NO}_{2}\right)_{2}$ as a precursor and characterized by chemical analysis using the ICP-AES method, XRD, TEM, FTIR and BET surface area determination. The oxidation reaction was carried out at $70^{\circ} \mathrm{C}$ under atmospheric pressure. The results showed the catalytic performance of $P t / \mathrm{Al}_{2} \mathrm{O}_{3}$ as being very high in terms of turnover frequency.
\end{abstract}

Keywords. Oxidation; cyclohexane; platinum; TBHP; cyclohexanol; cyclohexanone.

\section{Introduction}

A mixture of cyclohexanone and cyclohexanol known as K/A oil is obtained by cyclohexane oxidation. These two compounds are important intermediates in the manufacture of nylon-6 and nylon-6-6 which have become important reference materials in the industrial production of polymers, and the demand has expanded over the last few years. The industrial scale preparation of cyclohexanol and cyclohexanone is carried out by oxidation of cyclohexane or by hydrogenation of phenol (Schuchardt et al 1993, 2001; Lu et al 2005). The earlier process is carried out at around $150^{\circ} \mathrm{C}$ and 1-2 MPa pressure, employing metal cobalt salt or metal-boric acid as homogeneous catalyst worldwide. The drawback of this process is that the oxidation must be operated in 3-6\% conversion of cyclohexane to maintain a high selectivity (75-80\%) for the K/A oil (Ingold 1989; Sawatari et al 2001). Many attempts have been made to synthesize more efficient catalysts for the oxidation of cyclohexane. Bellifa et al (2006) used a $\mathrm{V}_{2} \mathrm{O}_{5}-\mathrm{TiO}_{2}$ catalyst which resulted in an $8 \%$ conversion and a $76 \%$ selectivity to cyclohexanol using acetic acid as solvent and acetone as initiator. Copper (II) complexes were used with $\mathrm{H}_{2} \mathrm{O}_{2}$ to give a total yield of $68.9 \%$ of cyclohexanol, cyclohexanone and other products in $24 \mathrm{~h}$ (Silva et al 2007). The use of $\mathrm{Co}_{3} \mathrm{O}_{4}$ nanocrystals gave a $7.6 \%$ conversion yielding cyclohexanol and cyclohexanone at $120^{\circ} \mathrm{C}$ in $6 \mathrm{~h}$ with molecular oxygen (Zhou et al 2005). A chromium

*Author for correspondence (cba@ mail.univ-tlemcen.dz) containing complex, CrCoAPO- $5\left(\mathrm{CH}_{3} \mathrm{COOH}\right)$ (Masters et al 2001) gave a 50\% conversion, yielding 55\%, 8\%, $15 \%$ and $22 \%$ selectivities towards cyclohexanol, cyclohexanone, adipic acid and others, respectively at $115^{\circ} \mathrm{C}$ and $1 \mathrm{MPa}$ of oxygen. The Co/ZSM-5 catalyst (Yuan et al 2006) was reported to give about $10 \%$ mol conversion and $97 \%$ selectivity to cyclohexanone and cyclohexanol at $120^{\circ} \mathrm{C}$ and $1.0 \mathrm{MPa}$ pressure of $\mathrm{O}_{2}$. A zirconium complex bonded to modify carbamate silica gel gave a product distribution ratio of $6 \cdot 6: 1$ of cyclohexanol/cyclohexene mixture with $21 \%$ conversion at $200^{\circ} \mathrm{C}$ (Anisia and Kumar 2004). Titanium silicate (Reddy and Sivasankar 1991) gave $27.8 \mathrm{~mol} \%$ conversion with selectivities of $44 \mathrm{~mol} \%$, $45 \mathrm{~mol} \%$ and $11 \mathrm{~mol} \%$ towards cyclohexanol, cyclohexanone and other products, respectively in a $5 \mathrm{~h}$ reaction at $100^{\circ} \mathrm{C}$ with hydrogen peroxide as oxidant. The $\mathrm{Au} / \mathrm{Al}_{2} \mathrm{O}_{3}$ system using molecular oxygen in a solvent free system resulted in $12.6 \%$ conversion with a selectivity of $52.6 \%$ for cyclohexanol and $32 \cdot 1 \%$ for cyclohexanone (Xu et al 2007). A similar use of Au/MCM-41 with oxygen resulted in $19 \%$ conversion with $21.3 \%$ and $6 \%$ selectivity towards cyclohexanol, cyclohexanone and other products, respectively ( $\mathrm{Lu}$ et al 2004). Ebadi et al (2007) reported Fe, Mn and CoPc supported on gamma-alumina as catalysts for aerobic oxidation of cyclohexane in the gas phase under atmospheric pressure. They obtained $38 \%$ of selectivity for cyclohexanol and cyclohexanone with $29 \%$ conversion of cyclohexane. Recently, Yao et al (2006) reported a conversion of $95 \%$ over Ce-MCM-41 at $100^{\circ} \mathrm{C}$ over $12 \mathrm{~h}$; this gave $82 \%$ selectivity to cyclohexanol. Sakthivel and Selvam (2002) reported 
a conversion of $99 \%$ yielding $82 \%$ and $6.6 \%$ selectivities towards cyclohexanol, and cyclohexanone, respectively using calcined Cr-MCM-41 catalyst. Here again, the reaction was carried out at $100^{\circ} \mathrm{C}$ and over a $12 \mathrm{~h}$ duration. This is by far the most promising catalyst reported in the literature to date. However, the long reaction time and high temperature are grounds for further improvement, and it is still difficult to apply these technologies to industrial processes.

Platinum catalyst, $\mathrm{Pt} / \mathrm{C}$, in the presence of $\mathrm{H}_{3} \mathrm{PMo}_{12} \mathrm{O}_{40} \cdot 14 \mathrm{H}_{2} \mathrm{O}$, an heteropoly compound, representing active catalytic systems for cyclohexane oxidation with a mixture of $\mathrm{O}_{2}$ and $\mathrm{H}_{2}$ gases and a selectivity of $64.8 \mu \mathrm{mol}$ for cyclohexanol and $16.9 \mu \mathrm{mol}$ for cyclohexanone was reported (Kuznetsova et al 2003). Radic et al (2004) conducted studies on the complete oxidation of hexane and toluene in the presence of $\mathrm{Pt} / \mathrm{Al}_{2} \mathrm{O}_{3}$. They demonstrated that the specific activity of hydrocarbons oxidation in the presence of catalysts based on supported platinum and palladium is known to depend on the size of metal crystallites (Carballo et al 1978; Kobayashi et al 1988; Marecot et al 1994; Labalme et al 1996; Pliangos et al 1997; Papaefthimiou et al 1998; Garetto and Apesteguia 2000). The development of specific activities based on the particle size of noble metals has been attributed to morphological effects of the metals and not to their chemical effects. The TOF of supported noble metals improved while increasing their size.

Here, we report Pt/oxides $\left(\mathrm{Al}_{2} \mathrm{O}_{3}, \mathrm{TiO}_{2}\right.$ and $\left.\mathrm{ZrO}_{2}\right)$ catalysts which show satisfactory conversion to the cyclohexane oxidation and selectivity of cyclohexanol and cyclohexanone using tertiobutyl hydroperoxide in $\mathrm{CH}_{3} \mathrm{CN}$ and $\mathrm{CH}_{3} \mathrm{COOH}$ as solvents.

\section{Experimental}

\subsection{Catalyst preparation}

The following supports, $\mathrm{Al}_{2} \mathrm{O}_{3}$ (Oxid C Degussa), $\mathrm{TiO}_{2}$ (Titandioxid Degussa), $\mathrm{ZrO}_{2}$ (Aldrich), of commercial grade were purchased in the form of nanopowder (in the range, 10-50 nm). They required further treatment before the impregnation of the metal precursors. The supports were mixed with water ( $200 \mathrm{~mL} \mathrm{H}_{2} \mathrm{O}$ for $100 \mathrm{~g}$ of support $)$ in order to form a paste. The latter was dried overnight at $120^{\circ} \mathrm{C}$, and then sieved to retain only the particles having a diameter ranging between 0.1 and $0.25 \mathrm{~nm}$. Then the support underwent calcination at $400^{\circ} \mathrm{C}$ under oxidative flow $\left(20 \% \mathrm{O}_{2}\right.$, $80 \% \mathrm{Ar}, 60 \mathrm{~mL} / \mathrm{min}$ ) during $4 \mathrm{~h}$.

An aqueous solution of $\mathrm{Pt}\left(\mathrm{NH}_{3}\right)_{2}\left(\mathrm{NO}_{2}\right)_{2}$ (Alfa Aesar) was then impregnated on these oxides in order to obtain 1 and 5\% wt. of platinum catalyst. After solvent evaporation, the solids were dried at $120^{\circ} \mathrm{C}$ overnight, then calcined at $400^{\circ} \mathrm{C}$ for $4 \mathrm{~h}$ under oxidative atmosphere (Ar: $48 \mathrm{~mL} / \mathrm{min}-$ $\mathrm{O}_{2}: 12 \mathrm{~mL} / \mathrm{min}$ ). Finally, the solids were reduced in $\mathrm{H}_{2}$ $(60 \mathrm{~mL} / \mathrm{min})$ at $400^{\circ} \mathrm{C}$ for $4 \mathrm{~h}$.

\subsection{Characterization}

Chemical composition of the samples were analysed by inductively coupled plasma-atomic emission spectroscopy (ICP-AES) using an OPTIMA 2000 DV spectrometer.

Diffractograms of the catalysts were obtained by X-ray diffraction (XRD) experiments performed on a Siemens D5005 powder diffractometer using $\mathrm{Cu} K \alpha$ radiation $(\lambda=$ $0.15186 \mathrm{~nm}$ ) and a backmonochromator. XRD patterns were recorded using $2 \mathrm{~s}$ dwell time, $0 \cdot 04^{\circ}$ step size and a constant divergence slit of 18. Crystalline planes were identified by comparison with PDF standards from ICDD.

The $\mathrm{N}_{2}$ adsorption-desorption measurements of supports were carried out at $-196^{\circ} \mathrm{C}$ using Micromeritics Tristar. Surface areas of all the supports were calculated using Brunauer-Emmett-Teller method, whereas Barrett-JoynerHalenda method was employed to get pore size distribution. Pore size distribution was obtained from desorption branch of isotherms.

The acidity of supports was characterized by pyridine adsorption followed by IR spectroscopy. IR spectra were recorded on a Nicolet Magna IR spectrometer using a thin wafer (16 $\mathrm{mm}$ in diameter, $\left.10-15 \mathrm{mg} \cdot \mathrm{cm}^{-2}\right)$ activated in situ in the IR cell under secondary vacuum $\left(10^{-3} \mathrm{~Pa}\right)$ at $200^{\circ} \mathrm{C}$ for $2 \mathrm{~h}$. Pyridine was adsorbed on the sample at $150^{\circ} \mathrm{C}$. The IR spectra were recorded at room temperature after activation and pyridine thermodesorption under vacuum $\left(10^{-3} \mathrm{~Pa}\right)$ for $1 \mathrm{~h}$ at $150^{\circ} \mathrm{C}$. The total amounts of Lewis acid sites accessible to pyridine were quantified by the subtraction between $P_{150}$ spectrum (spectrum of the catalyst after adsorption-desorption at $150^{\circ} \mathrm{C}$ of pyridine) and $P_{\text {ref }}$ (spectrum of the catalyst before adsorption of pyridine). This technique allowed on one hand elimination of the solid intrinsic absorbance in the wavelength range studied, and on another hand the ignorance of the pyridine physisorption influence (below $150^{\circ} \mathrm{C}$ ). Concentrations of Lewis acid sites able to retain pyridine adsorbed at $150^{\circ} \mathrm{C}$ were determined from the normalized absorbance areas of the band at $1455 \mathrm{~cm}^{-1}$ (PyL), using extinction coefficients previously determined. Spectra were also recorded after pyridine thermodesorption under vacuum $\left(10^{-3} \mathrm{~Pa}\right)$ for $1 \mathrm{~h}$ at $250^{\circ} \mathrm{C}, 350^{\circ} \mathrm{C}$ and $450^{\circ} \mathrm{C}$.

Electron microscopic studies of the catalysts were carried out on a JEOL $2000 \mathrm{FX}$ instrument operating at $200 \mathrm{kV}$. Catalyst specimens for electron microscopy were prepared by grinding the powder samples in an agate mortar, suspending and sonicating them in ethanol, and placing a drop of the suspension on a holey carbon copper grid. After evaporation of the solvent, the specimens were introduced into the microscope column. The area distribution of particles was determined by counting a large number of particles ( $>500$ ) on the TEM micrographs and by plotting $n_{i}$ as a function of $d_{i}$ ( $n_{i}$ is the number of particles within different intervals with given average diameters $d_{i}$ ). The mean surface diameter (Perkas et al 2005) of particles is then given by $d=\sum n_{i} d_{i}^{3} / \sum n_{i} d_{i}^{2}$. The measurements were done 
manually using the ImageJ program (Rasband and Image 1997-2005).

The chemisorption measurements were carried out in a glass volumetric catalyst system. Catalyst samples of $\sim 0.2 \mathrm{~g}$ were placed into a reactor and reduced with pure $\mathrm{H}_{2}$ for $2 \mathrm{~h}$ at $400^{\circ} \mathrm{C}$. After evacuating the catalysts at the same temperature for $2 \mathrm{~h}$, two adsorption isotherms (figure 1) were obtained at ambient temperature. The linear region of the first isotherm was extrapolated to zero pressure in order to calculate the amount of physisorbed and chemisorbed $\mathrm{H}_{2}\left(\mathrm{HC}_{T}\right)$. After an evacuation period of $1 \mathrm{~h}$, the second isotherm of $\mathrm{H}_{2}$ was obtained $\left(\mathrm{HC}_{R}\right)$. The same procedure (as the first isotherm) was used to calculate the amount of physisorbed species. The irreversibly held $\mathrm{H}_{2}$ was calculated from the difference between the two values. A 1/1 H/Pt stoichiometry was assumed in order to calculate the metallic dispersion. From the platinum dispersion, the mean diameter of the platinum particles $(d)$ was calculated using the formula:

$$
d(\mathrm{~nm})=\frac{5 \times 10^{3}}{\rho_{\mathrm{Pt}} \times S_{\mathrm{Pt}} \times D},
$$

where $\rho_{\mathrm{Pt}}$ is the Pt density $\left(21.4 \mathrm{~g} \cdot \mathrm{cm}^{3}\right), S_{\mathrm{Pt}}$ the specific area of $\mathrm{Pt}\left(275 \mathrm{~m}^{2} \cdot \mathrm{g}^{-1}\right)$ and $D$ the dispersion of platinum.

\subsection{Catalytic reactions}

The catalytic oxidation of cyclohexane with tertiobutyl hydroperoxide (TBHP) as the oxidant was carried out in a glass round-bottom flask with a magnetic stirrer and reflux condenser. First, commercial TBHP $70 \%$ in $\mathrm{H}_{2} \mathrm{O}$ (Aldrich) was stirred with cyclohexane in order to perform a phase transfer from water to cyclohexane. In a typical reaction,

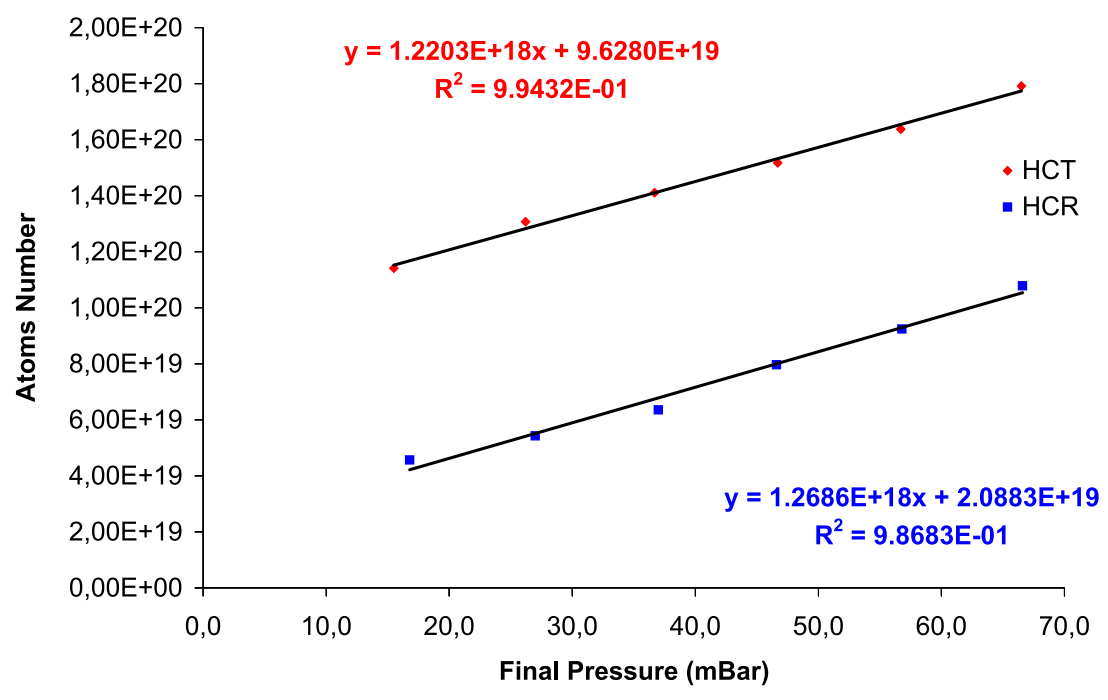

Figure 1. Example of hydrogen adsorption isotherms $\left(\mathrm{HC}_{T}\right)$ and $\left(\mathrm{HC}_{R}\right)$.

Table 1. Textural properties of catalysts and supports.

\begin{tabular}{|c|c|c|c|c|c|}
\hline \multirow[b]{2}{*}{ Catalysts } & \multirow[b]{2}{*}{$\begin{array}{c}\text { ICP } \\
\text { (wt. \%) }\end{array}$} & \multicolumn{4}{|c|}{ Supports } \\
\hline & & $\begin{array}{l}\text { Lewis acidity } \\
\left(\mu \mathrm{mol} \mathrm{g}^{-1}\right)\end{array}$ & $\begin{array}{l}\text { Surface area } \\
\left(\mathrm{m}^{2} \mathrm{~g}^{-1}\right)\end{array}$ & $\begin{array}{l}\text { Pore size } \\
\quad(\mathrm{nm})\end{array}$ & $\begin{array}{l}\text { Pore volume } \\
\left(\mathrm{cm}^{3} \mathrm{~g}^{-1}\right)\end{array}$ \\
\hline & 5.06 & & & & \\
\hline $\mathrm{Pt} / \mathrm{Al}_{2} \mathrm{O}_{3}$ & 1.02 & 150 & 95 & 31 & 0.72 \\
\hline & 4.94 & & & & \\
\hline $\mathrm{Pt} / \mathrm{ZrO}_{2}$ & 0.98 & 52 & 35 & 30 & 0.26 \\
\hline $\mathrm{Pt} / \mathrm{TiO}_{2}$ & $\begin{array}{l}5.00 \\
1.03\end{array}$ & 6 & 43 & 26 & 0.27 \\
\hline
\end{tabular}


Table 2. Metallic accessibility and crystallite size for various catalysts.

\begin{tabular}{|c|c|c|c|c|c|}
\hline \multirow[b]{2}{*}{ Catalyst } & \multirow[b]{2}{*}{$\begin{array}{c}\text { Metal } \\
\text { content }(\%)\end{array}$} & \multicolumn{2}{|c|}{ Chemisorption } & \multicolumn{2}{|c|}{ TEM } \\
\hline & & $\begin{array}{c}\text { Dispersion } \\
(\%)\end{array}$ & $\begin{array}{l}\text { Particle size } \\
\quad(\mathrm{nm})\end{array}$ & $\begin{array}{c}\text { Dispersion } \\
(\%)\end{array}$ & $\begin{array}{c}\text { Particle size }{ }^{b} \\
(\mathrm{~nm})\end{array}$ \\
\hline \multirow{2}{*}{$\mathrm{Pt} / \mathrm{Al}_{2} \mathrm{O}_{3}$} & 1.02 & 20 & $4 \cdot 7$ & l & l \\
\hline & $5 \cdot 06$ & 28 & $3 \cdot 3$ & 29 & $3 \cdot 2$ \\
\hline \multirow[t]{2}{*}{$\mathrm{Pt} / \mathrm{ZrO}_{2}$} & 0.98 & 31 & $3 \cdot 02$ & I & I \\
\hline & 4.94 & 42 & $2 \cdot 2$ & 54 & 1.7 \\
\hline \multirow[t]{2}{*}{$\mathrm{Pt} / \mathrm{TiO}_{2}$} & 1.03 & 60 & 1.5 & l & l \\
\hline & $5 \cdot 00$ & 52 & $1 \cdot 8$ & 54 & 1.7 \\
\hline
\end{tabular}

${ }^{\mathrm{a} C a l c u l a t e d ~ u p o n ~ t h e ~ n u m b e r ~ o f ~ a c c e s s i b l e ~ P t ~ u s i n g ~ c u b i c ~ p a r t i c l e ~ m o d e l ~ w i t h ~} 5$ accessible facets; $\mathrm{b}$ estimated from particle sizes using cubic particle model with 5 accessible facets. The surface area per Pt site $\left(a_{\mathrm{m}}\right)$ is taken as $8.08 \AA^{2}$.

$60 \mathrm{mmol}(6.5 \mathrm{~mL})$ of cyclohexane and $60 \mathrm{mmol}(8.5 \mathrm{~mL})$ of oxidant (TBHP) were mixed in a closed Erlenmeyer flask and magnetically stirred for $24 \mathrm{~h}$. The organic phase was then separated from the aqueous phase. In order to control the phase transfer, concentration of the remaining TBHP in the aqueous phase was determined by iodometric titration, and was found to be $<10 \%$. The solvent $(50 \mathrm{~mL}$ ) was then added to the TBHP-cyclohexane mixture. These reactants and solvent were introduced in a glass round-bottom flask and heated at $70^{\circ} \mathrm{C}$ under vigorous stirring. The catalyst $(0.05 \mathrm{~g})$ was subsequently added to the reaction mixture (time zero). The reaction products were identified by comparison with authentic products and the course of reactions was followed by gas chromatography (GC) using a Varian CP-3800 gas chromatograph equipped with a CP-WAX 52 $\mathrm{CB}$ column. A flame ionization detector (FID) was used and $0.5 \mu \mathrm{L}$ of the sample was analysed. Before $\mathrm{GC}$ analysis, the remaining TBHP was decomposed by introducing an excess of triphenylphosphine (Aldrich). On the other hand, to control this remaining TBHP, an iodometric titration was performed at the end of the reaction (after $6 \mathrm{~h}$ ) by testing the organic phase.

\section{Results and discussion}

\subsection{Textural properties}

Table 1 shows textural properties of catalysts and supports. $\mathrm{Al}_{2} \mathrm{O}_{3}$ support displays the largest BET surface area $\left(95 \mathrm{~m}^{2}\right.$. $\left.\mathrm{g}^{-1}\right)$ and pore volume, whereas $\mathrm{ZrO}_{2}$ has a lower BET area $\left(35 \mathrm{~m}^{2} \cdot \mathrm{g}^{-1}\right)$ and has the same pore volume as that of $\mathrm{TiO}_{2}$ which presents a BET area of $43 \mathrm{~m}^{2} \cdot \mathrm{g}^{-1}$. These supports display the same pore size $(30 \mathrm{~nm})$. On the other hand, IR spectra of pyridine adsorption showed the presence of Lewis acid sites $\left(1455 \mathrm{~cm}^{-1}\right)$ in all supports. We note the absence of characteristic bands of pyridine adsorption on Brønsted acid sites (formation of pyridinium ion leading to two adsorption bands at $1545 \mathrm{~cm}^{-1}$ and $\left.1637 \mathrm{~cm}^{-1}\right) . \mathrm{Al}_{2} \mathrm{O}_{3}$ support is

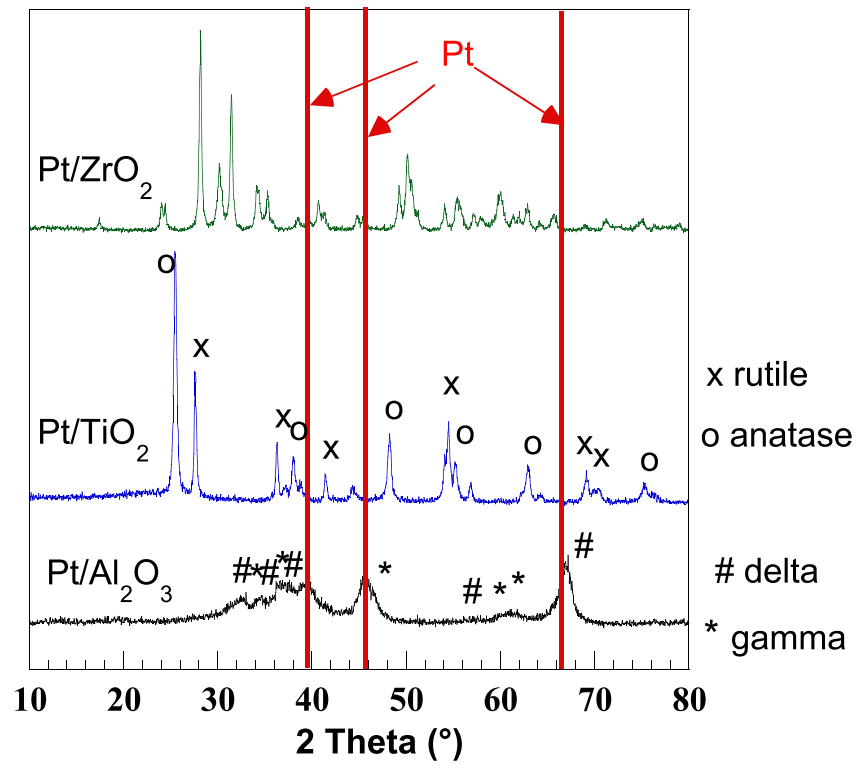

Figure 2. XRD patterns of catalysts.

acidic $\left(150 \mu \mathrm{mol} \cdot \mathrm{g}^{-1}\right.$ at $\left.150^{\circ} \mathrm{C}\right)$ compared to $\mathrm{ZrO}_{2}$ and $\mathrm{TiO}_{2}$ which have $52 \mu \mathrm{mol} \cdot \mathrm{g}^{-1}$ at $150^{\circ} \mathrm{C}$ and $6 \mu \mathrm{mol} \cdot \mathrm{g}^{-1}$ at $150^{\circ} \mathrm{C}$, respectively. As measured by ICP-AES, the platinum content in all catalysts is 1 or $5 \%$.

\subsection{Metal dispersion}

The metal dispersion of catalysts was obtained by $\mathrm{H}_{2}$ chemisorption at $25^{\circ} \mathrm{C}$. The percentage dispersion of metallic Pt was calculated assuming an H/M atomic ratio (Corma et al 1997) of 1 as shown in table 2 .

It is noteworthy to mention that the $5 \% \quad \mathrm{Pt} / \mathrm{Al}_{2} \mathrm{O}_{3}$ catalyst gave lower dispersion than the $5 \% \mathrm{Pt} / \mathrm{TiO}_{2}$, likely due to the acidic media. The Lewis acidity of the samples (table 1) decreases in the following order: $\mathrm{Al}_{2} \mathrm{O}_{3}>\mathrm{ZrO}_{2}>\mathrm{TiO}_{2}$. The smallest particle size was obtained for $\mathrm{Pt} / \mathrm{TiO}_{2}$ catalyst $(1.8 \mathrm{~nm})$ while the biggest corresponded to $\mathrm{Pt} / \mathrm{Al}_{2} \mathrm{O}_{3}$ 
$(3 \cdot 3 \mathrm{~nm})$. The deposited catalysts on $\mathrm{ZrO}_{2}$ showed the formation of particles of $\sim 2 \mathrm{~nm}$ in size. This proved to be considerably smaller than the mesopore diameter, indicating that incorporation of the particles in the mesopores could readily occur. Additionally, the $1 \%$ Pt catalysts gave lower dispersion than the $5 \% \mathrm{Pt}$ ones. By correlating the metal particle sizes to pore volumes, we can deduce that large particles are formed in the presence of $\mathrm{Pt} / \mathrm{Al}_{2} \mathrm{O}_{3}\left(0.72 \mathrm{~cm}^{3} \mathrm{~g}^{-1}\right)$
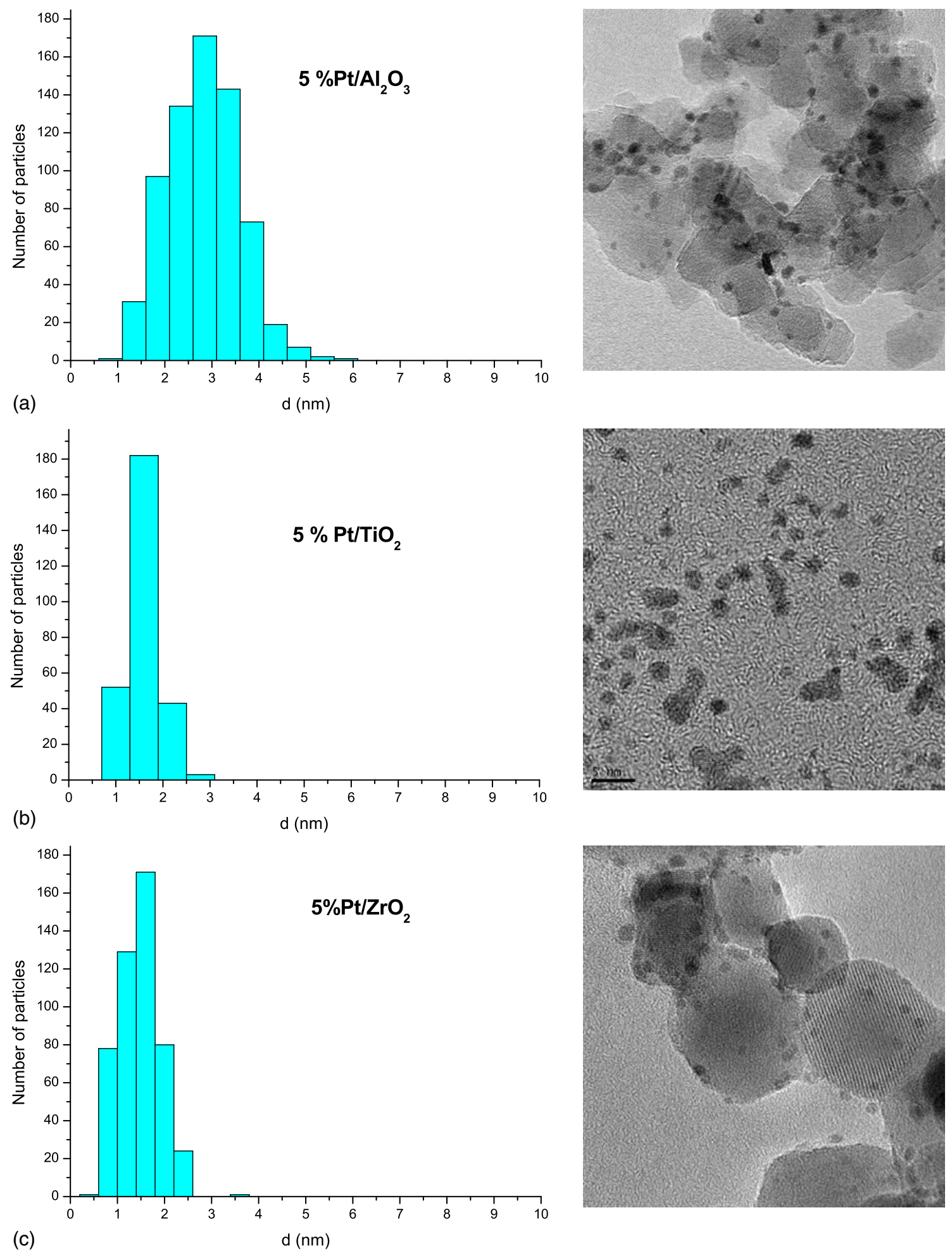

Figure 3. TEM photos of catalysts and particle size distribution: $\mathrm{Pt} / \mathrm{Al}_{2} \mathrm{O}_{3}(\mathbf{a}), \mathrm{Pt} / \mathrm{TiO}_{2}$ (b) and $\mathrm{Pt} / \mathrm{ZrO}_{2}$ (c). 


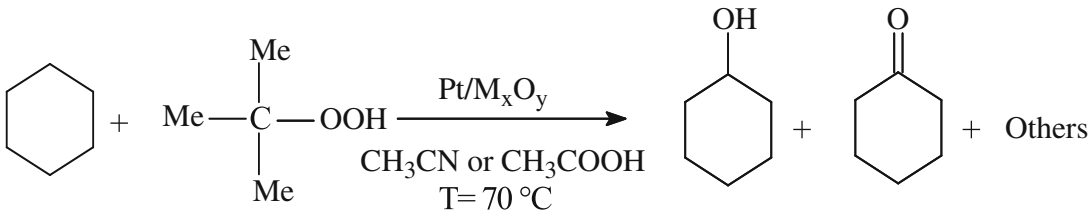

Scheme 1. Catalytic oxydation of cyclohexane to cyclohexanone and cyclohexanol.

Table 3. Oxidation of cyclohexane with different catalysts.

\begin{tabular}{|c|c|c|c|c|c|c|c|c|c|c|}
\hline \multirow[b]{3}{*}{ Support } & \multirow[b]{3}{*}{ wt. $(\%)$} & \multirow[b]{3}{*}{$d(\mathrm{~nm})$} & \multicolumn{4}{|c|}{ Acetic acid } & \multicolumn{4}{|c|}{ Acetonitrile } \\
\hline & & & \multirow[b]{2}{*}{$\operatorname{TOF}\left(\mathrm{h}^{-1}\right)$} & \multicolumn{3}{|c|}{ Selectivity (mmol) } & \multirow[b]{2}{*}{ TOF $\left(\mathrm{h}^{-1}\right)$} & \multicolumn{3}{|c|}{ Selectivity (mmol) } \\
\hline & & & & $\mathrm{Ol}$ & One & Others & & $\mathrm{Ol}$ & One & Others \\
\hline \multirow[t]{2}{*}{$\mathrm{Al}_{2} \mathrm{O}_{3}$} & 5.06 & $3 \cdot 34$ & 782 & $2 \cdot 8$ & 0.7 & $13 \cdot 54$ & 481 & $0 \cdot 5$ & 0 & 10 \\
\hline & 1.02 & $4 \cdot 68$ & 2830 & 2 & 0.56 & $6 \cdot 32$ & 1377 & 1.5 & 0 & $2 \cdot 8$ \\
\hline \multirow[t]{2}{*}{$\mathrm{TiO}_{2}$} & $5 \cdot 00$ & $2 \cdot 18$ & 169 & 4 & 1.4 & $6 \cdot 6$ & 95 & 1 & 0.5 & $2 \cdot 1$ \\
\hline & 1.03 & $1 \cdot 56$ & 793 & 0.92 & 0.45 & 7.63 & 520 & 0.4 & 0 & $4 \cdot 4$ \\
\hline \multirow[t]{2}{*}{$\mathrm{ZrO}_{2}$} & 4.94 & 1.80 & 440 & 1.8 & 2 & $13 \cdot 6$ & 334 & 0.5 & 0 & $12 \cdot 7$ \\
\hline & 0.98 & 3.02 & 1412 & 1 & $0 \cdot 3$ & $5 \cdot 3$ & 1155 & $0 \cdot 4$ & 0 & 5 \\
\hline
\end{tabular}

$\mathrm{C}_{6} \mathrm{H}_{12}=6.5 \mathrm{~mL} ; \mathrm{TBHP}=8.5 \mathrm{~mL}$; solvent $=50 \mathrm{~mL}$; catalyser $=0.05 \mathrm{~g} ; t=6 \mathrm{~h} ; T=70^{\circ} \mathrm{C}$;

$\mathrm{TOF}=$ mole of converted cyclohexane per unit time per mole of dispersed platinum.

while smaller ones are formed in the presence of $\mathrm{Pt} / \mathrm{TiO}_{2}$ and $\mathrm{Pt} / \mathrm{ZrO}_{2}\left(0 \cdot 27 \mathrm{~cm}^{3} \mathrm{~g}^{-1}\right)$.

\subsection{XRD characterization}

All diffractograms (figure 2) confirm that metallic platinum is present in catalysts as a result of the reduction step and no platinum oxide is observed. Metallic $\mathrm{Pt}$ is indicated by peaks at $39 \cdot 76^{\circ}, 46 \cdot 24^{\circ}$ and $67 \cdot 45^{\circ} 2 \theta$. Alumina-based catalyst shows two crystalline phases with sharper peaks, indicating that alumina is in $\delta$ and $\gamma$ forms. The diffractogram of the supported catalyst on $\mathrm{TiO}_{2}$ shows the two well known titanium oxide crystalline phases, viz. anatase and rutile, and only weak diffraction peaks of platinum are shown. Zirconia support is highly crystalline resulting in very intense peaks and the Pt metallics species can be seen as well.

\subsection{TEM characterization}

The TEM pictures of the prepared catalysts are shown in figure 3. The $5 \% \mathrm{Pt} / \mathrm{Al}_{2} \mathrm{O}_{3}$ catalyst sample was well dispersed with no indication of agglomeration of the Pt particles (figure 3a). The particle size was found to be in the range of $1.5-6 \mathrm{~nm}$, the diameter being mostly $2-4 \mathrm{~nm}$. The $5 \%$ $\mathrm{Pt} / \mathrm{TiO}_{2}$ had a narrow size distribution of particles in the range of $1-2.5 \mathrm{~nm}$ with a mean surface diameter of $1.73 \mathrm{~nm}$ (figure $3 b$ ). From the direct TEM micrographs (figure 3c), it may be noted that the $\mathrm{ZrO}_{2}$ support had a more irregular morphology. It was coated by small particles of platinum. On the other hand, the TEM pictures of $5 \% \mathrm{Pt} / \mathrm{ZrO}_{2}$ indicated showed particles in the range $1-2.5 \mathrm{~nm}$ but also larger particles of platinum up to $3.5 \mathrm{~nm}$ (figure $3 \mathrm{c}$ ). Similar surface diameters of Pt particles $(1.73 \mathrm{~nm})$ are shown in $5 \% \mathrm{Pt} / \mathrm{TiO}_{2}$ and $5 \% \mathrm{Pt} / \mathrm{ZrO}_{2}$. The same particle sizes were obtained for catalysts based on $\mathrm{TiO}_{2}$ and $\mathrm{ZrO}_{2}$ by Perkas et al (2005). On the other hand, the crystallite sizes estimated by chemisorption of $\mathrm{H}_{2}$ are the same which confirm the results (table 2).

\subsection{Cyclohexane oxidation}

Kinetic studies of the catalytic oxidation of cyclohexane with TBHP as oxidant, in acetonitrile or acetic acid as solvent at $70^{\circ} \mathrm{C}$ were performed on different samples. The desired products are cyclohexanol $\left(\mathrm{C}_{6} \mathrm{H}_{11} \mathrm{OH}\right)$, cyclohexanone $\left(\mathrm{C}_{6} \mathrm{H}_{10} \mathrm{O}\right)$ (scheme 1), but other products like cyclohexyl hydroperoxide, adipic acid, ester dicyclohexyl adipate, hexanolactone, and other esters (Zhou et al 2005), cyclohexyl acetate (Kumar et al 2009) did also form. In general, cyclohexyl hydroperoxide can be easily converted into cyclohexanol by reduction with a variety of reducing agents, thus increasing the yield of the target compounds. For this study, we focused on the selectivity towards olone only (cyclohexanol and cyclohexanone). The amount of the used catalyst was 
$0.05 \mathrm{~g}$ and the cyclohexane to TBHP mole ratio was (1:1). The results are shown in table 3 .

In the preliminary experiments, a non-catalyzed oxidation reaction was carried out under typical reaction conditions and no oxidative products were formed.

Moreover, to check the impact of the supports on the cyclohexane oxidation reaction, we tested them as catalysts (figures 4-6). All supports exhibited conversions $<15 \%$ and good selectivities (around 30\%), as expected from the results of Bellifa et al (2006) and Zhao et al (2006). All the supports are active during the oxidation of cyclohexane but the presence of metal clearly improves the activity of the reaction. This improvement is not the same for all samples although the Pt content is the same and particle sizes are very close.

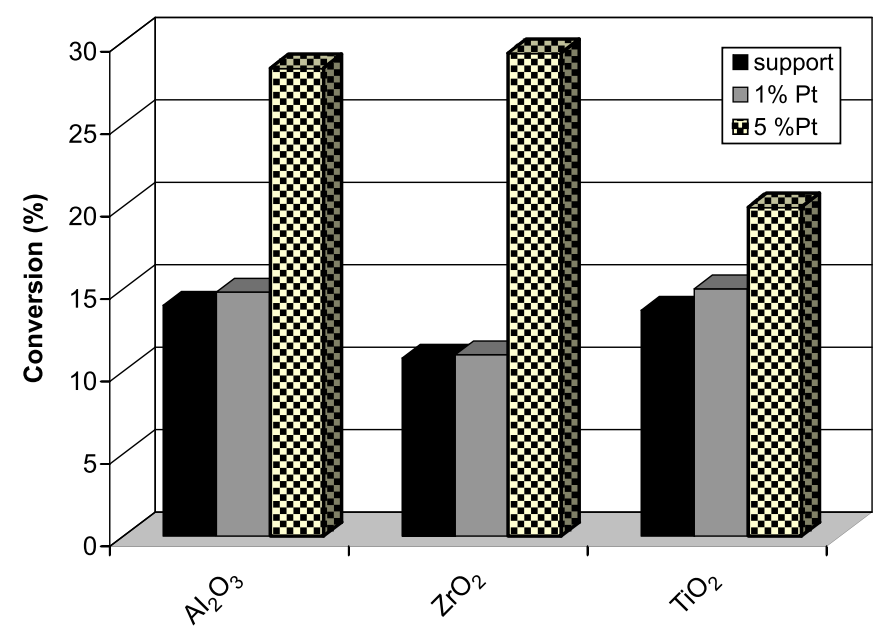

Figure 4. Effect of supports on activity of catalysts $\left(\mathrm{C}_{6} \mathrm{H}_{12}=\right.$ $60 \mathrm{mmol} ; \mathrm{TBHP}=60 \mathrm{mmol}$; acetic acid $=50 \mathrm{~mL}$; catalyst $=$ $0.05 \mathrm{~g} ; t=6 \mathrm{~h} ; T=70^{\circ} \mathrm{C}$ ).

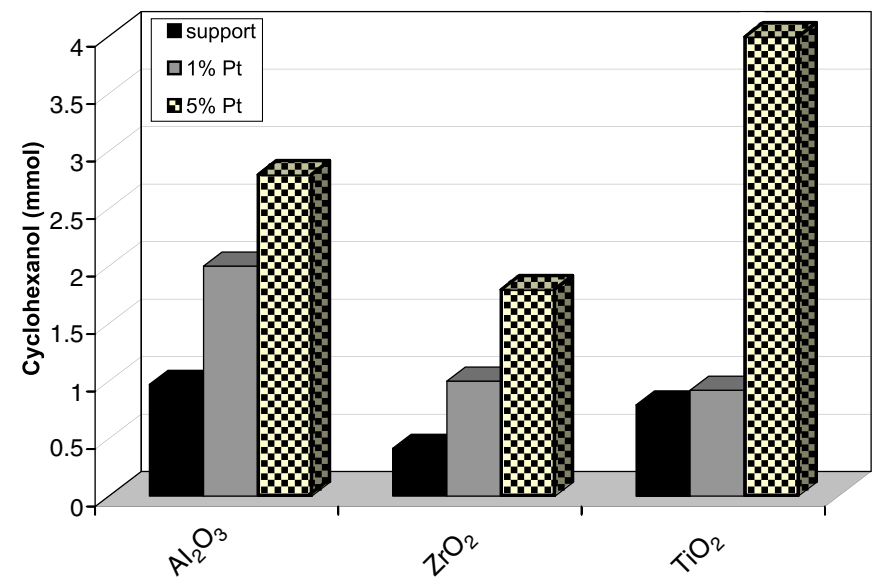

Figure 5. Selectivity of cyclohexanol as function of supports $\left(\mathrm{C}_{6} \mathrm{H}_{12}=60 \mathrm{mmol}\right.$; TBHP $=60 \mathrm{mmol}$; acetic acid $=50 \mathrm{~mL}$; catalyst $\left.=0.05 \mathrm{~g} ; t=6 \mathrm{~h} ; T=70^{\circ} \mathrm{C}\right)$.
Cyclohexanol and cylohexanone selectivities increase with metal content. The $1 \%$ catalysts showed a modest increase compared to the $5 \%$ ones. So, we can assume that the support participates in the reaction via a functional mechanism (support and metal), as concluded by Wangcheng et al (2008).

The solvent usually determines the medium polarity and plays an important role in the activity of catalysts (Pires et al 2000), but the main action of solvent is still to facilitate homogeneity of immiscible liquid phase. No significant effect of solvent has been reported for cyclohexane oxidation. The effects of solvent on the catalytic activity of cyclohexane oxidation over $\mathrm{Pt} / \mathrm{M}_{x} \mathrm{O}_{y}$ are also depicted in table 3 . In presence of acetic acid, cyclohexanol and cyclohexanone selectivities of alumina catalyst change a bit with the metal contents. We only observed an increase in the byproduct selectivity. It increases from $6.3 \mathrm{mmol}$ for $1 \%$ to $13.5 \mathrm{mmol}$ for $5 \%$. The activity drops when the platinum content increases.

In the presence of acetonitrile, it is clear that platinum does not promote the formation of cyclohexanone. The cyclohexanol selectivity decreases when the platinum content increases from 1 to $5 \%$. As with acetic acid, the activity decreases with an increase in platinum.

Comparing the two solvents, we find that the acetic acid leads to higher selectivities. Furthermore, high activities are obtained under acidic conditions compared to those obtained in acetonitrile medium, and they decrease when the platinum content increases. $1 \% \mathrm{Pt} / \mathrm{TiO}_{2}$ did not give cyclohexanone in acetonitrile. Low cyclohexanol selectivity is obtained, however, the amount of byproducts is much greater. This means that platinum directs the reaction to other products other than oxidation to cyclohexanol and cyclohexanone. For contents of 5\% platinum, cyclohexanone is produced. In the acid medium, $4 \mathrm{mmol}$ of cyclohexanol and $1.4 \mathrm{mmol}$ of

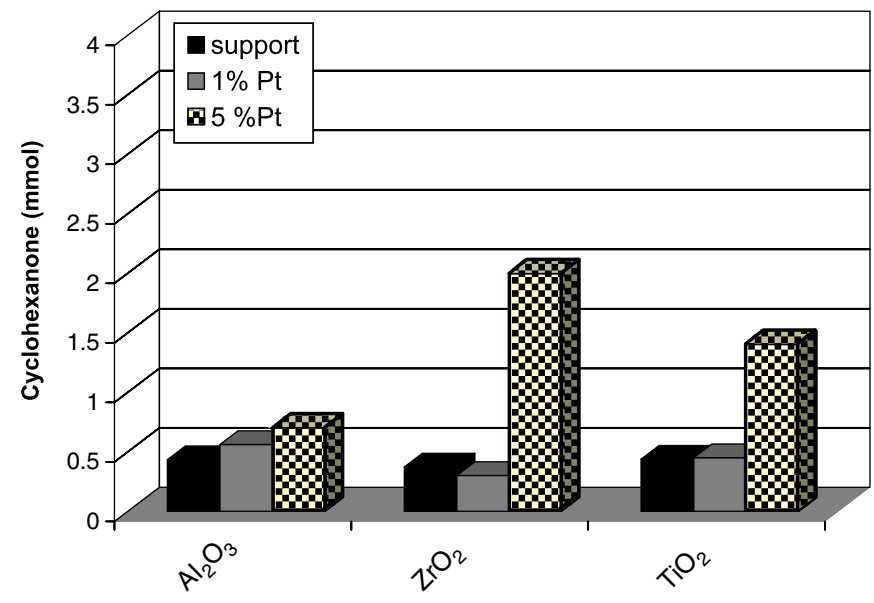

Figure 6. Selectivity of cyclohexanone as function of supports $\left(\mathrm{C}_{6} \mathrm{H}_{12}=60 \mathrm{mmol}\right.$; $\mathrm{TBHP}=60 \mathrm{mmol}$; acetic acid $=50 \mathrm{~mL}$; catalyst $=0.05 \mathrm{~g} ; t=6 \mathrm{~h} ; T=70^{\circ} \mathrm{C}$ ). 
cyclohexanone are produced and the selectivity in products does not exceed $1 \mathrm{mmol}$. In acetonitrile medium, lower selectivities of olone mixtures (cyclohexanol + cyclohexanone) are obtained and the amount of byproducts becomes important.

Regarding the catalysts of platinum supported on zirconium oxide, the evolution of cyclohexanol selectivity with regard to the metal content is less pronounced in the presence of acetonitrile. Indeed, we observe no increase in selectivity when the platinum content increases and no production of cyclohexanone is visible. The formation of byproducts increases significantly with the platinum content to about $12.6 \mathrm{mmol}$ in the presence of acetonitrile and $13.6 \mathrm{mmol}$ in the presence of acetic acid. We can see that these catalysts lead mainly to products other than olone mixing.

Apparently, $\mathrm{Pt} / \mathrm{TiO}_{2}$ catalyst has the best performance in acetic acid. The higher selectivity of $\mathrm{Pt} / \mathrm{TiO}_{2}$ in acetic acid compared to acetonitrile may be explained in the same way as in Du et al (2009). As is known, enhancement of the activity by acetic acid in the oxidation of cyclohexane has been reported in the literature (Shulpin et al 1999; Sooknoi and Limtrakul 2002). In acetic acid, TBHP is stabler and diminishes the self-decomposition by forming peroxyacetic acid. Cyclohexane and TBHP are dissolved in acetic acid and the reaction products (cyclohexanol and cyclohexanone) are not only soluble in the reaction mixture but can also be displaced from the catalyst surface as they formed.

As listed in table 3, acetonitrile is not a perfect solvent for cyclohexane oxidation over Pt catalysts. The best catalytic performance was obtained in the presence of acetic acid which presents a turnover frequency (TOF) of $2830 \mathrm{~h}^{-1}$ over $1 \% \mathrm{Pt} / \mathrm{Al}_{2} \mathrm{O}_{3}$. Furthermore and surprisingly, the high TOF was attained over $1 \% \mathrm{Pt} /$ oxides.

However, as the platinum loadings of our samples increased from 1 to $5 \%$, both the conversion of cyclohexane and the total selectivity to the products increased, and a sharp decrease of the TOF value became evident at the same time. These effects are more likely caused by a decrease of highly active Pt particles since the particles grow bigger according to the TEM analysis.

\section{Conclusions}

Various oxide supported Pt catalysts were investigated for oxidation of cyclohexane with TBHP. The main conclusions are:

(I) XRD analysis showed that metallic platinum is present in catalysts and no oxide was observed.

(II) All the supports are active during oxidation of cyclohexane but the presence of metal clearly improves activity of the reaction.

(III) Activity depends on the acidity of the support or $\mathrm{Pt}$ particles size and can be ordered as follows:

$$
\mathrm{Pt} / \mathrm{Al}_{2} \mathrm{O}_{3}>\mathrm{Pt} / \mathrm{ZrO}_{2}>\mathrm{Pt} / \mathrm{TiO}_{2} \text {. }
$$

(IV) Acetic acid as a solvent is better than acetonitrile, since acetic acid gave high conversion and high selectivity to cyclohexanol.

\section{Acknowledgement}

Authors thank the Algerian Ministry of Higher Education and Scientific Research for the fellowship funding in University of Poitiers, France.

\section{References}

Anisia K S and Kumar A 2004 Appl. Catal. A: Gen. 273193

Bellifa A, Lahcene D, Technar Y N, Choukchou-Braham A, Bachir R, Bedrane S and Kappenstein C 2006 Appl. Catal. A: Gen. 3051

Carballo L, Serrano C, Wolf E E and Carberry J 1978 J. Catal. 52507

Corma F, Sepulveda-Escribano A, Fierro J L and RodriguezReinoso F 1997 Appl. Catal. A: Gen. 150165

Du Y, Xiong Y, Li J and Yang X 2009 J. Mol. Catal. A: Chem. 29812

Ebadi A, Safari N and Peyrovi M H 2007 Appl. Catal. A: Gen. 321135

Garetto T F and Apesteguia C R 2000 Catal. Today 62189

Ingold K U 1989 Aldrichim. Acta 2269

Kobayashi M, Kanno T, Konishi A and Takeda H 1988 React. Kinet. Catal. Lett. 3789

Kumar R, Sithambarama S and Suib S L 2009 J. Catal. 262304

Kuznetsova N I, Kirillova N V, Kuznetsova L I and Likholobov V A 2003 J. Mol. Catal. A: Chem. 204-205 591

Labalme V, Garbowsky E, Ghilhaume N and Primet M 1996 Appl. Catal. A: Gen. 13893

Lu G, Zhao R, Qian G, Qi Y, Wang X and Suo J 2004 Catal. Lett. 97115

Lu G, Ji D, Qian G, Qi Y, Wang X and Suo J 2005 Appl. Catal. A: Gen. 280175

Marecot P, Fakche A, Kellali B, Mabilon G, Prigent M and Barbier J 1994 Appl. Catal. B: Environ. 3283

Masters A F, Beattie J K and Roa A L 2001 Catal. Lett. 75159

Papaefthimiou P, Ioannides T and Verykios X E 1998 Appl. Catal. B: Environ. 1575

Perkas N, Minh D P, Gallezot P, Gedanken A and Besson M 2005 Appl. Catal. B: Environ. 59121

Pires E L, Magalhaes J C and Schuchardt U 2000 Appl. Catal. A: Gen. 203231

Pliangos C, Yentekakis I V, Papadakis V G, Vayenas C G and Verykios X E 1997 Appl. Catal. B: Environ. 14161

Radic N, Grbic B and Terlecki-Baricevic A 2004 Appl. Catal. B: Environ. 50153

Rasband W and Image J 1997-2005 U.S. National Institutes of Health, Bethesda, MD, USA http://rsb.info.nih.gov/ij/

Reddy J S and Sivasanker S 1991 Catal. Lett. 11241

Sakthivel A and Selvam P 2002 J. Catal. 211134

Sawatari N, Yokota T, Sakaguchi S and Ishii Y 2001 J. Org. Chem. 667889

Schuchardt U, Carvalho W A and Spinace E V 1993 Synlett. 713

Schuchardt U et al 2001 Appl. Catal. A: Gen. 2111

Shulpin G B, Fink G S and Smith J R 1999 Tetrahedron 555345 
Silva A C et al 2007 Appl. Catal. A: Gen. 317154

Sooknoi T and Limtrakul J 2002 Appl. Catal. A: Gen. 233 227

Wangcheng Z, Guanzhong L, Yanglong G, Yun G, Yanqin W, Yunsong W, Zhigang Z and Xiaohui L 2008 J. Rare Earths 26 515

Xu L X, He C H, Zhu M Q and Fang S 2007 Catal. Lett. 114 202
Yao W, Chen Y, Min L, Fang H, Yan Z, Wang H and Wang J 2006 J. Mol. Catal. A: Chem. 246162

Yuan H X, Xia Q H, Zhan H J, Lu X H and Su K X 2006 Appl. Catal. A: Gen. 304178

Zhao R, Wang Y, Guo Y, Guo Y, Liu X, Zhang Z, Wang Y, Zhan W and Lu G 2006 Green Chem. 8459

Zhou L, Xu J, Miau H, Wang F and Li X 2005 Appl. Catal. A: Gen. 292223 